\title{
NUCLEAR COLOCALIZATION AND COMPLEX FORMATION OF INSULIN WITH RETINOBLASTOMA PROTEIN IN HEPG2 HUMAN HEPATOMA CELLS
}

\author{
RAZVAN T. RADULESCU, ERIKA DOKLEA, KAI KEHE AND HARALD MÜCKTER
}

Walther-Straub-Institut für Pharmakologie und Toxikologie, Ludwig-Maximilians-Universität, Nußbaumstraße 26, 80336 München, Germany

\begin{abstract}
Previous structural and biochemical evidence had suggested that insulin may bind to the nuclear tumor suppressor retinoblastoma protein $(\mathrm{RB})$. The present study is now the first to unravel the physical and functional interaction between a growth factor and an anti-oncoprotein, specifically demonstrating the association between insulin and RB in living cells and finding that this complex formation is relevant for cell division. Our immunofluorescence microscopy data suggest that insulin colocalizes with RB in the cell nuclei of HepG2 human hepatoma cells and that it contacts the B-region of the RB pocket. Furthermore, these events were found to correlate with an enhancement of cell proliferation. These results are in line with the initial structure-based predictions and, moreover, provide a suitable starting point for the further understanding as well as the pharmacological modulation of nucleocrine interactions between growth factors and tumor suppressors, in physiology and disease.

Journal of Endocrinology (2000) 166, R1-R4
\end{abstract}

\section{Introduction}

Insulin is a major hormone in the circulation regulating glucose homeostasis and bioavailability, yet it is also an important growth factor for normal and neoplastic cells. Its action is still interpreted as to result solely from its interaction with its cell membrane receptor and the signaling cascades ensuing therefrom (1). By contrast, a previous analysis of insulin's amino acid sequence had already suggested that, intriguingly, insulin may also bind to the nuclear tumor suppressor $\mathrm{RB}$ which is known to play a central role in the control of cell cycle progression (2). Subsequently, the RB peptide proposed to be the contact site for insulin was shown to recognize full-length human insulin in vitro (3). Based on these studies, we addressed the question whether insulin could also be found to associate with RB in living cells. We chose as a model the HepG2 human hepatoma cells which have already been shown to contain normal RB (4). We now report that insulin translocates to the nuclei of these cells where it associates with RB, more specifically with the Bregion of the $R B$ pocket, and that this complex formation coincides with an increase in cell division.

\section{Materials and Methods}

Cell Lines and Tissue Culture. HepG2 cells (ATCC), a human hepatocellular carcinoma cell line, were grown in RPMI medium (Life Technologies) supplemented with 5\% FCS (Biochrom).
Internalization Experiments and Immunofluorescence Microscopy. HepG2 cells were seeded on cover slips, allowed to adhere and subsequently incubated without serum for about $48 \mathrm{hr}$. The cells were then treated with bovine insulin (Sigma) at $100 \mu \mathrm{g} / \mathrm{ml}$ RPMI for $30-60$ $\min$ at $37^{\circ} \mathrm{C}$. Following this treatment, cells were processed according to a previously described protocol (5). Briefly, cells were fixed with $2 \%$ paraformaldehyde for $30 \mathrm{~min}$ at $4^{\circ} \mathrm{C}$ and permeabilized with $0.2 \%$ Triton X100 for $5 \mathrm{~min}$ at room temperature. Cells were then incubated with primary antibodies for $90 \mathrm{~min}$ and subsequently with fluorescently labeled secondary antibodies for $30 \mathrm{~min}$. Finally, nuclei were counterstained with Hoechst 33342 dye (Serva Feinbiochemica) and mounted with ProLong antifade (Molecular Probes) for immunofluorescence microscopy. Antibodies and dilutions for the experiments were the following: mouse anti-human RB primary antibodies (Fig.1) G3-245 (Pharmingen) which recognizes the RB epitope 332344 1:100 and XZ91 (Dunn Labortechnik) which binds to the RB site 620-665 (6) 1:20, guinea pig antihuman insulin antibody A0564 (Dako) 1:20, Cy3labeled goat anti-mouse secondary antibody (Amersham Pharmacia Biotech) 1:50 and Alexa-488-labeled goat anti-guinea pig secondary antibody (MoBiTec) 1:100. Fluorescein-isothiocyanate (FITC)-labeled MCR-10 peptide (7) was a gift from Pichem, Inc. (Graz, Austria) and employed at a $50 \mu$ molar concentration. Stained cells were examined using an Axio-

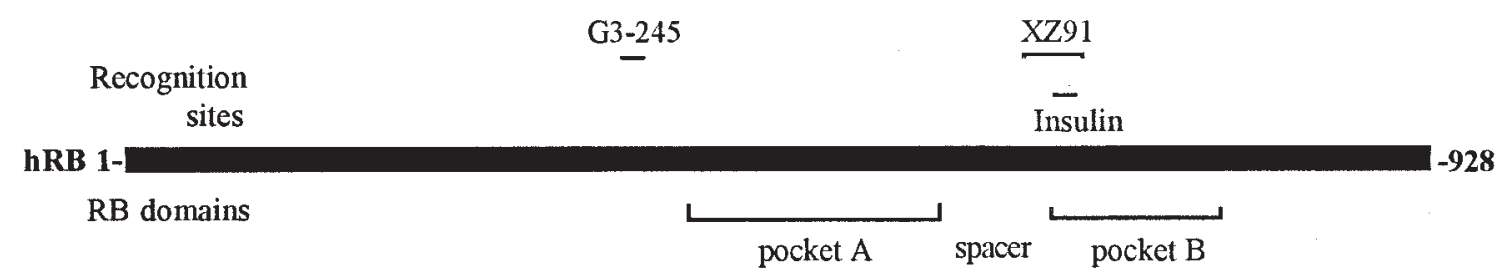

FIG. 1 Main RB domains, RB epitopes for anti-RB Abs G3-245 \& XZ91 and proposed RB binding site for insulin 

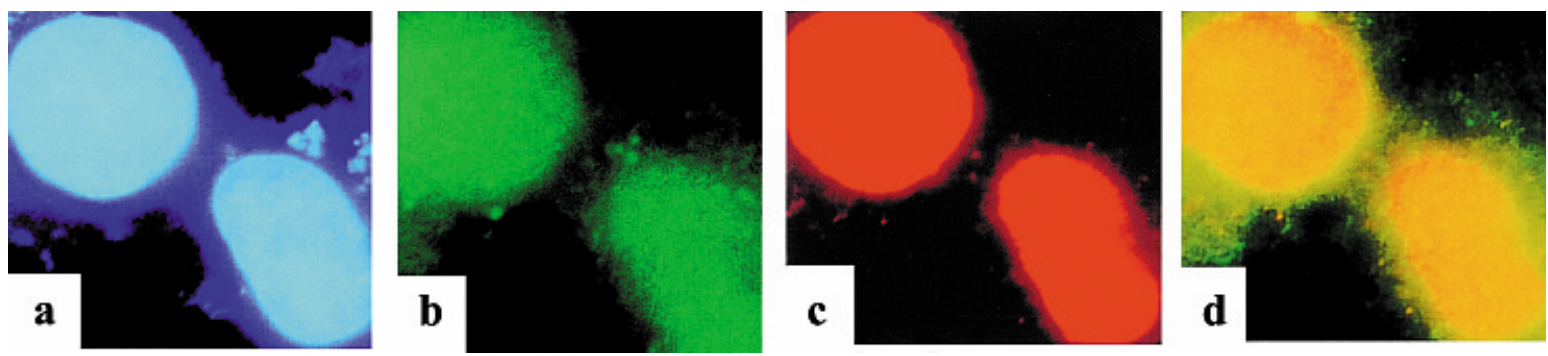

FIG. 2 Colocalization of insulin and RB in HepG2 nuclei whereby anti-RB Ab G3-245 generates a strong nuclear RB signal. (a) Hoechst 33342, (b) anti-insulin Ab, (c) anti-RB Ab G3-245, and (d) overlay of b \& c.

skop microscope (Zeiss) with a x100 objective. Images were captured using 400 ASA slide films (Kodak). Cell Proliferation Assay. HepG2 cells were seeded at 100,000 cells $/ \mathrm{ml} \mathrm{RPMI} / 5 \%$ FCS in a total volume of $3 \mathrm{ml}$ in Petri dishes with grids, allowed to adhere and subsequently incubated without serum for about $48 \mathrm{hr}$. The cells were counted in 4 to 5 different visual fields per dish for a first time as a baseline, using an Axiovert $35 \mathrm{M}$ microscope (Zeiss) with a $\times 32$ objective. The cells were then treated in the presence of $\mathrm{RPMI} / 5 \%$ FCS with bovine insulin (Sigma) at $100 \mu \mathrm{g} / \mathrm{ml}$ and/or $50 \mu \mathrm{M}$ FITC-MCR-10-peptide for $3-4$ days at $37^{\circ} \mathrm{C}$ vs. RPMI $/ 5 \%$ FCS alone as a control. Subsequently, the cells were counted again in the same areas as mentioned above. This experiment was repeated twice.

\section{Results}

In a first series of experiments, we found that, following a 30-minute incubation of HepG2 cells with insulin at $100 \mu \mathrm{g} / \mathrm{ml}(17 \mu \mathrm{M})$, the hormone was present in the nuclei (Fig. 2a) of the majority of the cells (Fig. 2b). The fluorescence signal was also detected in the cytoplasm, yet the fluorescence intensity was clearly higher in the nuclear compartment, suggesting that the predominant quantity of insulin had translocated to the nucleus. No signal was evident with the fluorescently labeled secondary antibody alone (not shown). On the other hand, RB could be visualized by means of the anti-RB antibody G3-245 in most HepG2 nuclei, with only a faint staining in the cytoplasm (Fig. 2c). The overlay then yielded that insulin and RB colocalize in the nuclei of these cells (Fig. 2d).

In order to more conclusively determine whether this nuclear colocalization also involved a physical association between these two proteins, we
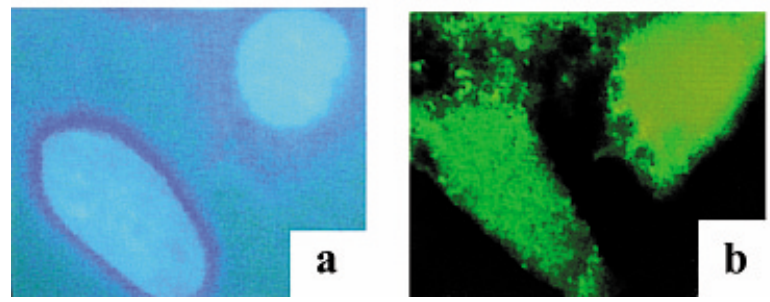

performed a second series of experiments whereby we explored whether insulin could compete with an anti$\mathrm{RB}$ antibody, namely XZ91, for the same RB binding site. In other words, we addressed the question whether insulin added to the cells prior to the specific anti-RB antibody would be able to cause the masking of the RB epitope of this antibody (Fig. 1) which is located in a region spanning $R B$ amino acids $620-665$ (6) and thus includes $R_{649-654}$ (Fig. 1), the proposed RB binding site for insulin (2). Fig. 3c suggests that this is the case since the fluorescence signal elicited by XZ91 in the cell nuclei, as identified by the Hoechst stain in Fig. 3a, is considerably fainter than the G3-245 signal (Fig. 2c) which is the result of an interaction of the latter antibody with the $\mathrm{N}$-terminus of RB where insulin is not predicted to bind. Fig. $3 \mathrm{~b}$ shows that insulin has translocated to the nucleus in this setting too and Fig. $3 d$ reveals the colocalization of $R B$ and insulin by merging the anti-RB and anti-insulin images.

To further verify whether the fainter staining with XZ91 vs. G3-245 is indeed a result of the prior RB epitope masking by insulin, we slightly increased the time of incubation with insulin to 1 hour since extending the time of exposure of the cells to insulin has previously been shown to increase the amount of insulin accumulating in the nucleus (8). We also employed FITC-MCR-10 (7), a fluorescently labeled peptide containing the proposed RB binding site for insulin in competition studies. As such, we observed in this third series of experiments that insulin is able to extinguish the XZ91 signal (Fig. 4d vs. Fig. 4b) and that the nuclear RB peptide (Fig. 4f) reverses this event, yielding a strong XZ91 signal despite the presence of added insulin (Fig. 4g).
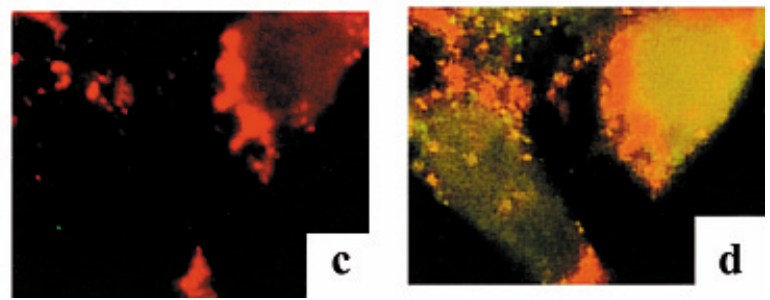

FIG. 3 Colocalization of insulin and RB in HepG2 nuclei whereby anti-RB Ab XZ91 yields only a weak nuclear RB signal. (a) Hoechst 33342, (b) anti-insulin Ab, (c) anti-RB Ab XZ91, and (d) overlay of b \& $c$. 

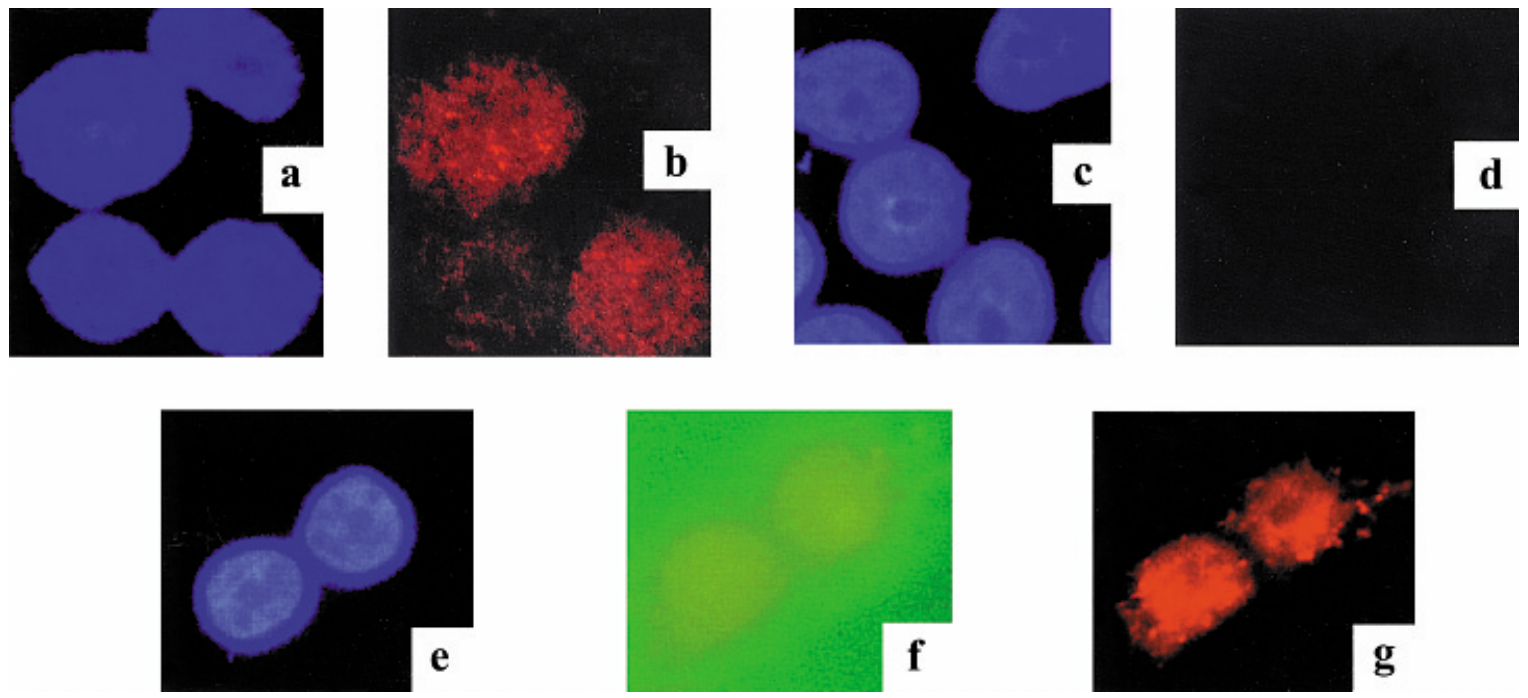

FIG. 4 1-hour incubation of HepG2 cells with insulin at $100 \mu \mathrm{g} / \mathrm{ml}$ completely masks the XZ91 epitope on RB and this event can be reversed by FITC-MCR-10. Control: (a) Hoechst $33342 \&$ (b) anti-RB Ab XZ91. Treatment with insulin at $100 \mu \mathrm{g} / \mathrm{ml}$ : (c) Hoechst 33342 \& (d) anti-RB Ab XZ91. Combined treatment with $50 \mu M$ FITC-MCR-10 and insulin at $100 \mu \mathrm{g} / \mathrm{ml}$ : (e) Hoechst 33342, (f) nuclear FITC-MCR-10 \& (g) anti-RB Ab XZ91.

To exclude that XZ91 has recognized FITCMCR-10 instead of RB, we also preincubated prior to its addition to the cells this peptide with the XZ91 antibody in a cuvette for 1 hour. If recognition had occurred, the peptide would have been precipitated during this preincubation and thus prevented from translocating into the nucleus and keeping insulin from concealing the XZ91 epitope on RB. However, we detected that the peptide localized to the nucleus and that XZ91 generated a potent RB signal (not shown).

Finally, we looked into the biological effects of insulin at the concentration at which we had observed its nuclear translocation and binding to RB, i.e. $100 \mu \mathrm{g} / \mathrm{ml}$. In one representative experiment, insulin was found to significantly augment HepG2 cell proliferation after 96 hours of co-incubation whereby the median relative cell number in the insulin-treated cell sample was 1.89 (reflecting an increase from 204 to 385 cells per visual field) compared to 1.34 (from 179 to 240 cells per visual field) in the control, thus meaning that insulin raised the cell number by about $40 \%$ over control values. This rise in proliferation consistently correlated with considerable morphological changes such as a larger cell size as well as a shift of the nucleus/cytoplasm ratio towards the nucleus and the appearance of prominent nucleoli (not shown). By contrast, FITC-MCR-10 reduced HepG2 proliferation despite the presence of added insulin, decreasing the cell number to a median relative value of 0,77 (from 176 to 135 cells per visual field), i.e. by about $40 \%$ below control values. This effect was accompanied by morphological changes towards cellular differentiation, yielding fibroblast-like spindle forms and neuronal shapes (not shown) similar to what is seen when normal RB is added to certain tumor cells.

\section{Discussion}

Insulin has previously been found to translocate to the cell nucleus of living cells (9). Although this finding is compatible with the nucleocrine model of an insulinRB complex (10), the proof for the occurrence of this interaction in vivo has still been pending. The current report is therefore a first step towards in vivo validation. As such, we show here by immunofluorescence microscopy that, at pharmacological concentrations (100 $\mu \mathrm{g} / \mathrm{ml}$ or $17 \mu \mathrm{M}$, respectively), insulin translocates into the muclei of the majority of living HepG2 cells which are both known to express normal RB (4) and to respond to insulin metabolically (11). By the same method, we demonstrate the colocalization and complex formation of insulin with RB. We infer from our data that, during the latter process, insulin binds the $\mathrm{B}$ region of the RB pocket, as anticipated (2). This is suggested by both the abrogation of the XZ91 RB recognition signal by insulin and the reversal of this event- resulting in a bright XZ91 RB staining- by FITC-MCR-10 (7) which contains the RB $649-654$ fragment previously proven to recognize insulin (3). In other words, FITC-MCR-10 has most likely competed with RB for insulin and, by binding insulin, prevented it from masking the XZ91 epitope on RB, thus allowing sufficient XZ91 to reach its target and generate a strong signal. In this context, the preincubation experiment suggested that XZ91 recognizes endogenous RB protein, and not added synthetic RB peptide.

In contrast, endogenous or added insulin is not able to extinguish or even diminish the immuno- 
fluorescence based on the G3-245 anti-RB antibody. This is in accordance with the previous predictions (2) since G3-245 recognizes an N-terminal epitope on RB (amino acids 332-344) that is not anticipated to participate in insulin-RB complex formation.

Furthermore, we observed that an anti-insulin fluorescence signal was also present in the nuclei of (serum-deprived) HepG2 cells that had not been preincubated with insulin (not shown), suggesting that these subcellular structures contain endogenously produced insulin with presumably autocrine functions. However, this signal was overall weaker than that in the nuclei of the cells pretreated with insulin. Under these baseline conditions, i.e. where no insulin had been added, the XZ91 RB signal was again fainter than the G3-245 RB signal (not shown). This may be due to the selective disturbance of the binding of XZ91 to $\mathrm{RB}$ by both endogenous nuclear insulin and other cellular proteins known to associate with the RB pocket such as D-type cyclins.

We finally found that insulin, at the same concentration at which it visibly colocalizes with $R B$ in the majority of HepG2 nuclei and interferes with XZ91 binding to RB, also increases the number of HepG2 cells and causes them to assume a morphology that is characteristic of proliferating cells, implying that the binding of insulin to RB has a stimulating effect on cell proliferation. This had been correctly deduced from the initial structural analysis of insulin and its comparison with RB-binding viral oncoproteins (2).

The insulin concentration employed here is high. This experimental condition appears nevertheless reasonable. It has previously been reported that insulin translocates to the cell nucleus in a dosedependent fashion, and this rather occurs in dose ranges above the concentrations known to stimulate the insulin receptors on the cell membrane (8). Moreover, in insulin-producing tumors the amount of insulin should be much higher than the insulin concentration of around $10 \mathrm{nM}$ which is sufficient to activate the insulin receptor tyrosine kinase and also than the insulin concentration used by us here. This view is supported by a previous investigation into the insulin content of insulinomas that unraveled high pathological concentrations of insulin $(0,1-1 \mathrm{mM})$ in these neoplastic tissues (12).

Interactions between growth factors and other proteins in the nuclei of living cells, e.g. between FGF and casein kinase II (13) or IGF-1 and IGFBP-3 (14), have already been reported. However, the occurrence of an association between insulin and $\mathrm{RB}$ in vivo, as outlined here for the first time, should be particularly important since, as a result of RB's immediate link to the genes, such a complex may enable insulin to directly influence the cell's decision to divide or not.

\section{Acknowledgment}

We thank Prof. Wolfgang Forth for encouragement and steady support.

\section{References}

1. Myers MG Jr and White MF 1996 Insulin signal transduction and the IRS proteins. Annu Rev Pharmacol Toxicol 36: 615-658

2. Radulescu RT and Wendtner CM 1992 Proposed interaction between insulin and retinoblastoma protein. J Mol Recognit 5: 133-137

3. Radulescu RT, Bellitti MR, Ruvo M, Cassani G and Fassina G 1995 Binding of the LXCXE insulin motif to a hexapeptide derived from retinoblastoma protein. Biochem Biophys Res Commun 206: 97-102

4. Puisieux A, Galvin K, Troalen F, Bressac B, Marcais C, Galun E, Ponchel F, Yakicier C, Ji J and Ozturk M 1993 Retinoblastoma and p53 tumor suppressor genes in human hepatoma cell lines. FASEB J 7: 1407-1413

5. Neufeld KL and White RL 1997 Nuclear and cytoplasmic localizations of the adenomatous polyposis coli protein. Proc Natl Acad Sci USA 94: 3034-3039

6. Hu Q, Bautista C, Edwards GM, DefeoJones D, Jones RE and Harlow E 1991 Antibodies specific for the human retinoblastoma protein identify a family of related polypeptides. Mol Cell Biol 11: 5792-5799

7. Radulescu RT and Jaques G 2000 Selective inhibition of human lung cancer cell growth by peptides derived from retinoblastoma protein. Biochem Biophys Res Commun 267: 71-76

8. Smith RM and Jarett L 1990 Partial characterization of mechanism of insulin accumulation in H35 hepatoma cell nuclei. Diabetes 39: 683-689

9. Goldfine ID , Jones AL, Hradek GT, Wong KY and Mooney JS 1978 Entry of insulin into human cultured lymphocytes: electron microscope autoradiographic analysis. Science 202: 760-763

10. Radulescu RT 1995 From insulin, retinoblastoma protein and the insulin receptor to a new model on growth factor specificity: the nucleocrine pathway. J Endocrinol 146: 365-368

11. Podskalny JM, Takeda S, Silverman RE, Tran D, Carpentier JL, Orci L and Gorden P 1985 Insulin receptors and bioresponses in a human liver cell line (Hep G-2). Eur J Biochem 150: 401-7

12. Berger $M$, Bordi $C$, Cüppers H-J, Berchtold P, Gries FA, Müntefering H, Sailer R, Zimmermann $H$ and Orci L 1983 Functional and morphologic characterization of human insulinomas. Diabetes 32: 921-931

13. Bailly K, Soulet F, Leroy D, Amalric F and Bouche G 2000 Uncoupling of cell proliferation and differentiation activities of basic fibroblast growth factor. FASEB J 14: 333-344

14. Li W, Fawcett J, Widmer HR, Fielder PJ, Rabkin R and Keller G-A 1997 Nuclear transport of insulin-like growth factor-I and insulin-like growth factor binding protein-3 in opossum kidney cells. Endocrinology 138: 1763-1766 